\title{
Caracterização físíca e hídrica em solos dos Tabuleiros Costeiros no Distrito de Irrigação Platô de Neópolis
}

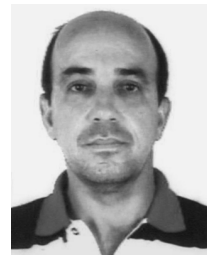

Fernando L. D. Cintra ${ }^{1}$, Jeane C. Portela ${ }^{2}$ \& Luis C. Nogueira ${ }^{3}$

1 Embrapa Tabuleiros Costeiros. Av. Beira Mar 3250, CEP 4001-970, Aracaju, SE. Fone: (79) 226-1310, Fax: (79) $226-1369$. E-mail: fcintra@cpatc.embrapa.br (Foto)

2 Embrapa Tabuleiros Costeiros. E-mail: jeane@cpatc.embrapa.br

3 Embrapa Tabuleiros Costeiros. E-mail: nogueira@cpatc.embrapa.br

Protocolo 56 - 2/4/2003 - Aprovado em 6/2/2004

\begin{abstract}
Resumo: Dentre os principais problemas relacionados á produção de fruteiras no Distrito de Irrigação Platô de Neópolis, destaca-se a carência de informações sobre os atributos físíco e hídricos dos solos e suas relações com o manejo da irrigação e a produtividade das culturas. Este fato assume grande relevância, em virtude da provável existência de variações significativas entre os solos quanto á capacidade de armazenamento e suprimento de água para as plantas, e suas conseqüências na eficácia da irrigação e no custo da atividade agrícola. A comparação entre as áreas estudadas indicou que, apesar da proximidade e de se situarem no mesmo plano da paisagem, as propriedades físicas e hídricas foram afetadas pelas camadas coesas, em intensidade variável, a depender da posição ocupada no perfil do solo e do grau do adensamento apresentado, ante o que se acredita ser necessário a adoção de cuidados especiais e, diferenciados, na seleção das práticas de manejo do solo e da irrigação, como forma de promover o desenvolvimento da fruticultura no Platô de Neópolis.
\end{abstract}

Palavras-chave: caracterização do solo, propriedades físicas, irrigação

\section{Characterization of physical and water attributes of the Coastal Tablelands soils in Irrigation District of "Platô de Neópolis"}

\begin{abstract}
The lack of information about physical and water attributes in soils and their relationships with the irrigation management and crop productivity is one of the most important problem related to productivity of fruit crops at the Irrigation District of "Platô de Neopolis". This fact is of great relevance considering the clear evidence of the occurrence of expressive soil variations, regarding the water holding capacity and plant water supplies in such soils and the consequences in irrigation effectiveness and crop costs. Despite the proximity of the areas and their location in the same landscape, their physical and water proprieties are affected in different intensities by the hardened soil layers, depending on the position in soil profile and degree of soil hardening, thus it is necessary to adopt specific and differentiated pratices of soil and irrigation management for the development of fruit crop in the "Platô de Neópolis".
\end{abstract}

Key words: physical properties, irrigation, soil characteristics

\section{INTRODUÇÃO}

Os Tabuleiros Costeiros exercem papel relevante no cenário econômico do Nordeste pois, além de gerar emprego e renda para a maioria da população, contribuem com parte expressiva da receita proveniente da atividade agropecuária (Cuenca, 2001). A fruticultura é uma das atividades mais significativas do agronegócio desse ecossistema, visto que envolve rede de transporte, armazenagem e distribuição, motivo pelo qual representa, hoje, uma das suas principais vocações. Um dos fatores que têm contribuído para a expansão da fruticultura é a predominância de extensas áreas de solo com relevo plano a suave ondulado, que permitem intensificar os cultivos contribuindo, assim, para elevação da produtividade das fruteiras e manutenção da relação custo/benefício das explorações, em patamares competitivos.

A influência da fruticultura nos Tabuleiros do Estado de Sergipe é sentida sobretudo pelo aumento constante de áreas irrigadas, a exemplo do Distrito de Irrigação Platô de Neópolis, SE, cujo projeto foi idealizado para promover a produção de frutas visando tanto ao mercado interno quanto ao externo. Apesar do agronegócio ser considerado rentável, são vários 
os problemas enfrentados pela cadeia produtiva, destacandose as relações entre as propriedades físicas dos solos e os fatores físicos de crescimento, cuja combinação, se inadequada, poderá promover quedas significativas na produtividade e elevação dos custos de produção, principalmente em sistemas irrigados.

Segundo Ribeiro (1991) o uso dos solos dos tabuleiros para irrigação deve ser acompanhado de estudos e pesquisas que visem resolver, entre outros impasses, aqueles criados pela presença de horizontes coesos. Matsura et al (2001) assinalam que áreas extensas dos distritos de irrigação do País são cultivadas de maneira uniforme, trazendo problemas nas estratégias de manejo, em virtude da variabilidade espacial e temporal dos atributos relacionados ao sistema solo-águaplanta-atmosfera. No Platô de Neópolis, a aparente homogeneidade das propriedades físicas dos solos, associada à uniformidade da paisagem, faz com que os produtores utilizem, indistintamente, os mesmos volumes de água e freqüências de irrigação, sem se considerar os diferentes níveis de adensamento dos horizontes coesos, sua posição no perfil e, conseqüentemente, as alterações que promovem no regime hídrico do solo.

Os horizontes coesos, com alta densidade e baixa condutividade hidráulica, impõem condições inadequadas aos fatores físicos de crescimento e promovem danos no desenvolvimento das culturas. Forsythe (1967) estabelece diferenças claras entre propriedades físicas e fatores físicos de crescimento; segundo ele, as propriedades físicas: textura, infiltração de água, densidade do solo e condutividade hidráulica, entre outras, influenciam os fatores físicos de crescimento: potencial total de água no solo, aeração, temperatura e resistência mecânica à penetração das raízes.

Objetivou-se, com este trabalho, realizar a caracterização física e hídrica de solos no Distrito de Irrigação Platô de Neópolis, visando contribuir para ajustes no sistema de produção da fruticultura irrigada. Espera-se que as informações obtidas, além de melhorar a produtividade das fruteiras, contribuam também para a economia de água e energia e preserve os mananciais através da racionalização da água utilizada na irrigação. Neste aspecto, reportagem publicada em revista de circulação nacional* alerta para o problema através do texto reproduzido a seguir: "Uma pressão desabusada é exercida sobre os ecossistemas de água doce, que têm sido destruídos pela poluição e pelo uso descontrolado. Sete de cada dez litros utilizados pelo homem são destinados à agricultura, e mais da metade dela é perdida em sistemas de irrigação ineficientes.

\section{MATERIAL E MÉTODOS}

O estudo foi desenvolvido em dois lotes do Distrito de Irrigação Platô de Neópolis, SE, Empresas União (lote 04) e H. Dantas (lote 24). O projeto tem área total de 10.432 ha, 7.000 dos quais irrigáveis e 3.132 de reserva ambiental e se compõe de 38 lotes com área média de 190 ha. Algumas das culturas exploradas

$\bar{*}$ Veja, v.35, n.33, p.85-87, 2000 são citros, manga, abacaxi, banana e coqueiro anão-verde, o qual ocupa área aproximada de $34,2 \%$ do projeto (dados obtidos em fevereiro de 2001, na ASCONDIR - Associação dos Concessionários do Distrito de Irrigação do Platô de Neópolis, $\mathrm{SE}$ ). Os lotes onde os estudos foram realizados têm, no coqueiro anão-verde, sua principal exploração.

O clima da região, segundo a classificação de Koppen, é tropical chuvoso com verão seco e precipitação pluvial em torno de $1.200 \mathrm{~mm}$ anuais, com chuvas concentradas nos meses de abril a setembro. A altitude é de aproximadamente $90 \mathrm{~m}$ e os solos são, em sua maioria, classificados como Argissolo Amarelo, com e sem fragipã, textura arenosa/média fase cerrado e cerrado subperenifólio, relevo plano e suave ondulado, sendo esta última sua principal característica. Verificam-se, na Figura 1, predominância na classe de solo Argissolo Amarelo e associa-

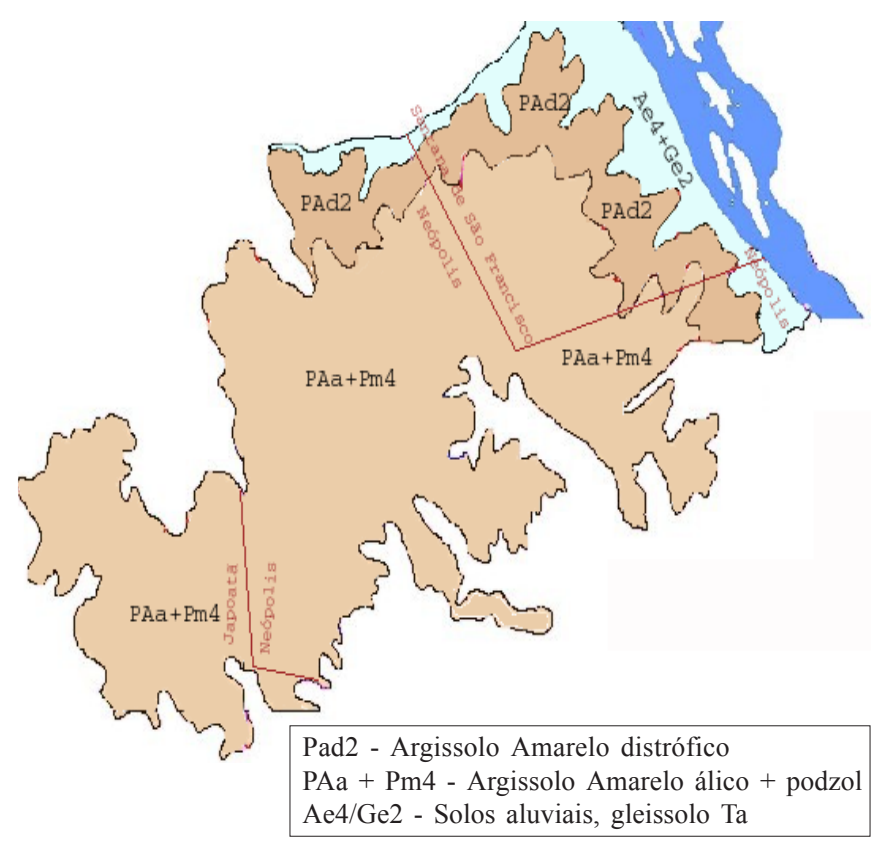

Figura 1. Classes de solo predominantes no Distrito de Irrigação Platô de Neópolis, SE

ções na área do Projeto.

\section{Parâmetros avaliados}

Granulometria e densidade das partículas: Utilizaram-se amostras com estrutura deformada, coletadas em camadas de solo com 0,20 m de espessura (H. Dantas) e 0,15 m e 0,30 m (União), até a profundidade de 1,2 m. Após secadas ao ar, desagregadas e passadas por peneira com $2 \mathrm{~mm}$ de abertura de malha, as amostras foram utilizadas para determinação da granulometria e densidade das partículas, com base em metodologia descrita no manual de métodos de análises físicas (EMBRAPA, 1997).

Curva de retenção, densidade do solo, porosidade: Para determinação das curvas de retenção de água foram utilizadas amostras com estrutura indeformada, coletadas em camadas de solo, nas seguintes profundidades, por área estudada: 0 - 0,20; 
$0,20-0,40 ; 0,40-0,60 ; 0,60-0,80 ; 0,80-1,00 ; 1,00-1,20 \mathrm{~m}, \mathrm{em} \mathrm{H}$. Dantas e $0-0,15 ; 0,15-0,30 ; 0,30-0,60 ; 0,60-0,90 ; 0,90-1,20 \mathrm{~m}$, no lote União. Coletaram-se dez amostras por camada, sendo oito para elaboração da curva de retenção e duas para determinação da densidade do solo, porosidade total, macro e microporosidade.

As amostras indeformadas foram coletadas utilizando-se aparelho tipo Uhland. Cada anel, com dimensões de 0,0599m de altura e $0,0537 \mathrm{~m}$ de diâmetro, foi subdividido em três segmentos iguais e separáveis para utilização apenas do anel central; assim, objetivou-se utilizar camada de solo que tenha sofrido o mínimo distúrbio possível na sua estrutura, durante o procedimento de coleta. Para elaboração da curva de retenção utilizaram-se as tensões 0,$5 ; 1 ; 4 ; 10 ; 33 ; 100 ; 500$ e $1500 \mathrm{kPa}$. Funis de placa porosa foram empregados para aplicação das tensões 0,$5 ; 1 ; 4 ; 5$ e $10 \mathrm{kPa}$, câmaras de baixa tensão para os pontos 33 e $100 \mathrm{kPa}$ e de alta tensão para os pontos 500 e 1500 $\mathrm{kPa}$. As amostras foram mantidas tanto nos funis como nas câmaras de pressão, pelo tempo necessário para atingir o equilíbrio, ou seja, o momento em que não mais houvesse drenagem de água.

O ajuste das curvas de retenção da água no solo se deu com base na equação de van Genuchten (1980), utilizando-se o software SWRC, desenvolvido por Dourado Neto et al. (1990). A equação considera o potencial mátrico $\left(\phi_{\mathrm{m}}\right)$, como variável independente e a umidade volumétrica $(\theta)$, como variável dependente:

$$
\theta=\theta_{\mathrm{r}}+\frac{\theta_{\mathrm{s}}-\theta_{\mathrm{r}}}{\left[1+\left(\alpha\left|\phi_{\mathrm{m}}\right|^{\mathrm{n}}\right)^{\mathrm{m}}\right.}
$$

donde:

$\theta_{\mathrm{r}} \quad$ - umidade volumétrica residual $\left(\mathrm{m}^{3} \mathrm{~m}^{-3}\right)$

$\theta_{\mathrm{s}} \quad$ - umidade volumétrica saturada $\left(\mathrm{m}^{3} \mathrm{~m}^{-3}\right)$

$\left|\phi_{\mathrm{m}}\right|$ - potencial mátrico $(\mathrm{kPa})$

$\alpha, \mathrm{m}, \mathrm{n}$ - parâmetros empíricos da equação

Considerou-se capacidade de campo (CC), a umidade do solo obtida com a aplicação da tensão de $10 \mathrm{kPa}$ e, como ponto de murcha permanente (PMP) a obtida com a tensão de 1500 $\mathrm{kPa}$. A água disponível foi determinada pela diferença entre CC e PMP. Para determinação da porosidade total, macro e micropo-rosidade, utilizaram-se funis de placa porosa para a aplicação individual da tensão de $5 \mathrm{kPa}$.

\section{RESULTADOS E DISCUSSÃO}

\section{Distribuição do tamanho das partículas Granulometria}

Na Figura 2 e Tabela 1, é possível se observar o caráter essencialmente arenoso dos solos das áreas estudadas e a aparente homogeneidade na distribuição granulométrica, ao longo do perfil. A diferença mais visível fica por conta dos teores de areia da camada superficial do solo, cuja classificação textural é areia para H. Dantas e areia franca para o lote União. Observa-se, no entanto, com base na segmentação da fração areia (Tabela 1), maior concentração de areia grossa e muito grossa e maiores percentuais de argila em H. Dantas, o que deve contribuir para promover diferenciações nos atributos físicos dos solos avaliados. Diferenças entre solos a partir do

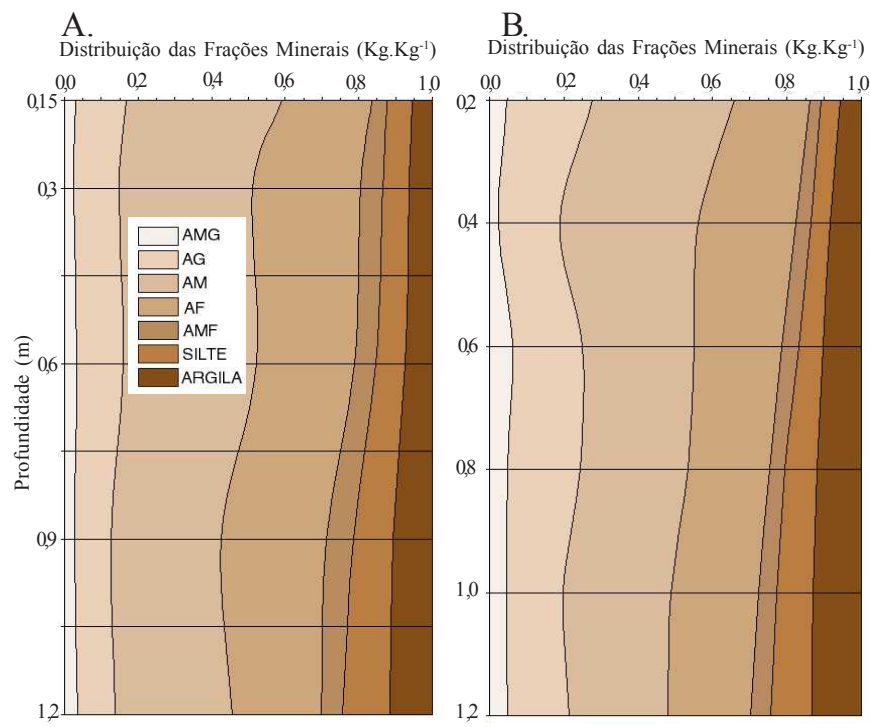

Figura 2. Distribuição do tamanho das partículas minerais em União (A)e H. Dantas (B)

Tabela 1 Distribuição do tamanho de partículas nas áreas experimentais $\left(\mathrm{g} \mathrm{kg}^{-1}\right)^{*}$

\begin{tabular}{|c|c|c|c|c|c|c|c|c|c|c|}
\hline \multirow{2}{*}{ Lote } & \multirow{2}{*}{$\begin{array}{l}\text { Profundidade } \\
\text { (m) }\end{array}$} & \multicolumn{5}{|c|}{ Distribuição da Fração Areia** } & \multirow{2}{*}{$\begin{array}{l}\text { Areia } \\
\text { Total }\end{array}$} & \multirow{2}{*}{ Silte } & \multirow{2}{*}{ Argila } & \multirow{2}{*}{$\begin{array}{c}\text { Classificação } \\
\text { Textural }\end{array}$} \\
\hline & & AMG & $\mathrm{AG}$ & $\mathrm{AM}$ & $\mathrm{AF}$ & AMF & & & & \\
\hline \multirow[t]{5}{*}{ União } & $0-0,15$ & 32,17 & 145,51 & 396,00 & 231,24 & 31,49 & 859,51 & 95,93 & 46,21 & Areia Franca \\
\hline & $0,15-0,30$ & 31,03 & 138,78 & 384,49 & 233,30 & 35,90 & 846,15 & 95,16 & 58,69 & Areia Franca \\
\hline & $0,30-0,60$ & 27,42 & 126,99 & 357,56 & 243,50 & 38,09 & 813,84 & 110,19 & 75,96 & Areia Franca \\
\hline & $0,60-0,90$ & 33,62 & 140,92 & 330,81 & 233,35 & 37,95 & 777,55 & 132,05 & 90,40 & Franco Arenoso \\
\hline & $0,90-1,20$ & 32,61 & 119,13 & 314,78 & 227,95 & 34,31 & 756,95 & 146,71 & 96,90 & Franco Arenoso \\
\hline Média & & 31,37 & 134,27 & 356,73 & 233,87 & 35,55 & 810,80 & 116,00 & 73,63 & \\
\hline \multirow[t]{6}{*}{ H Dantas } & $0-0,20$ & 45,32 & 230,37 & 384,17 & 202,56 & 29,68 & 892,11 & 50,23 & 57,66 & Areia \\
\hline & $0,20-0,40$ & 25,07 & 165,71 & 370,41 & 263,62 & 38,51 & 863,32 & 51,44 & 85,24 & Areia Franca \\
\hline & $0,40-0,60$ & 62,30 & 187,41 & 301,66 & 233,28 & 47,24 & 831,88 & 65,30 & 102,82 & Franco Arenoso \\
\hline & $0,60-0,80$ & 49,41 & 194,88 & 289,58 & 218,47 & 40,98 & 793,31 & 86,29 & 120,40 & Franco Arenoso \\
\hline & $0,80-1,00$ & 45,33 & 152,35 & 291,33 & 235,70 & 46,74 & 771,44 & 98,15 & 130,41 & Franco Arenoso \\
\hline & $1,00-1,20$ & 48,32 & 166,24 & 266,18 & 222,22 & 52,49 & 755,44 & 111,59 & 132,98 & Franco Arenoso \\
\hline Média & & 45,96 & 182,83 & 317,22 & 229,31 & 42,61 & 817.92 & 77,16 & 104,92 & \\
\hline
\end{tabular}

* Para se obter dados em percentagem, dividir por 10

** $\mathrm{AMG}=$ Areia Muito Grossa $(2 \mathrm{a} 1 \mathrm{~mm}), \mathrm{AG}=$ Areia Grossa $(1 \mathrm{a} 0,5 \mathrm{~mm}), \mathrm{AM}=$ Areia Média $(0,5$ a $0,25 \mathrm{~mm}), \mathrm{AF}=$ Areia Fina $(0,25 \mathrm{a} 0,1 \mathrm{~mm}), \mathrm{AMF}=\mathrm{Areia}$ Muito Fina $(0,1$ a $0,05 \mathrm{~mm})$ 
fracionamento da areia total, foram também observadas por Souza et al (2001), que reforçam a contribuição dessa prática na distribuição do tamanho dos poros e na manifestação da coesão.

Segundo Araújo Filho et al (2001), a cobertura pedológica dos Tabuleiros Costeiros é constituída por solos com acentuada variação textural entre os horizontes superficiais arenosos e os de subsuperfície, mais argilosos. No presente estudo, esta particularidade é percebida apenas no lote H. Dantas (Figura 2 e Tabela 1), em que o caráter mais arenoso da camada superficial do solo, o maior teor de argila em profundidade e os elevados valores de densidade do solo e das partículas (Tabela 2), devem estar incluídos entre os principais fatores responsáveis pela

Tabela 2. Densidade do solo (Ds), densidade de partícula (Dp), porosidade total, macro e microporosidade do solo, nos lotes do Distrito de Irrigação Platô de Neópolis, SE

\begin{tabular}{|c|c|c|c|c|c|c|}
\hline \multirow{2}{*}{ Lotes } & \multirow{2}{*}{$\begin{array}{l}\text { Profundidade } \\
\text { (m) }\end{array}$} & Ds & $\mathrm{Dp}$ & \multicolumn{3}{|c|}{ Porosidade* $\left(\mathrm{m}^{3} \mathrm{~m}^{-3}\right)$} \\
\hline & & \multicolumn{2}{|c|}{$\left(\mathrm{kg} \mathrm{m}^{-3}\right)$} & Macro & Micro & Total \\
\hline \multirow[t]{5}{*}{ União } & $0-0,15$ & 1,55 & 2,53 & 0,21 & 0,16 & 0,37 \\
\hline & $0,15-0,30$ & 1,58 & 2,56 & 0,18 & 0,17 & 0,35 \\
\hline & $0,30-0,60$ & 1,62 & 2,60 & 0,11 & 0,17 & 0,28 \\
\hline & $0,60-0,90$ & 1,59 & 2,55 & 0,12 & 0,19 & 0,31 \\
\hline & $0,90-1,20$ & 1,56 & 2,58 & 0,14 & 0,21 & 0,35 \\
\hline \multirow[t]{6}{*}{ H. Dantas } & $0-0,20$ & 1,63 & 2,60 & 0,20 & 0,18 & 0,38 \\
\hline & $0,20-0,40$ & 1,71 & 2,63 & 0,07 & 0,27 & 0,34 \\
\hline & $0,40-0,60$ & 1,68 & 2,65 & 0,11 & 0,22 & 0,33 \\
\hline & $0,60-0,80$ & 1,66 & 2,63 & 0,16 & 0,17 & 0,33 \\
\hline & $0,80-1,00$ & 1,65 & 2,65 & 0,16 & 0,17 & 0,33 \\
\hline & $1,00-1,20$ & 1,69 & 2,68 & 0,04 & 0,29 & 0,33 \\
\hline
\end{tabular}

* Para transformar em percentagem, multiplicar por 100

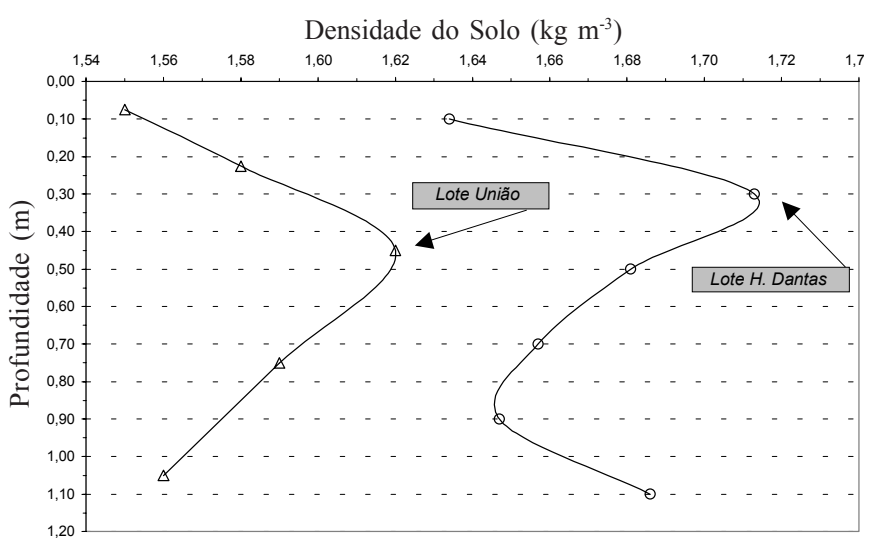

Figura 3. Densidades do solo nas áreas estudadas: Lotes União e H Dantas do Distrito de Irrigação Platô de Neópolis, SE

formação das camadas coesas apresentadas na Figura 3.

\section{Densidade do solo}

Por definição, o caráter coeso dos solos dos Tabuleiros Costeiros é uma característica pedogenética típica de horizontes de subsuperfície de textura média, argilosa ou muito argilosa, encontrados normalmente entre 0,30 e $0,70 \mathrm{~m}$ e, quando secos são duros a extremamente duros, tornando-se friáveis ou firmes quando úmidos (Ribeiro, 2001). Para avaliação da expressão da camada coesa, no entanto, é preciso se valer de diversos atributos físicos, em geral interrelacionados, dentre os quais se destaca a densidade do solo.

Aqui, entre os atributos físicos avaliados a densidade do solo foi o que apresentou a maior diferença na comparação entre as áreas estudadas. Observa-se, na Figura 3 e Tabela 2, que o valor máximo de $1,62 \mathrm{~kg} \mathrm{dm}^{-3}$, no lote União, é inferior ao valor mínimo de $1,63 \mathrm{~kg} \mathrm{dm}^{-3}$, em H. Dantas. As camadas mais adensadas em ambos os lotes variaram tanto em intensidade quanto em posicionamento no perfil do solo. Enquanto em $\mathrm{H}$. Dantas a densidade atinge índices muito elevados (valor máximo de $1,71 \mathrm{~kg} \mathrm{dm}^{-3}$ ) e se situa a $0,30 \mathrm{~m}$ da superfície, no lote União a camada adensada se encontra a $0,45 \mathrm{~m}$ de profundidade e apresenta índices de adensamento mais baixos (valor máximo de 1,62 $\mathrm{kg} \mathrm{dm}^{-3}$ ); além disso, verifica-se em H. Dantas um segundo ponto de adensamento a $1,10 \mathrm{~m}$, fato este não verificado no lote União (Figura 3). Situação similar à de H. Dantas foi descrita por Cintra (1997), na região Tabuleiro Sul de Sergipe, o qual chamou a atenção para o fato de que as camadas adensadas, posicionadas em diferentes pontos do perfil do solo, formavam uma zona de acumulação de umidade capaz de criar situações diferenciadas de fornecimento de água para as plantas, ao longo do ano.

A análise dos dados apresentados na Figura 3 e Tabela 2, permite inferir-se que no lote $\mathrm{H}$. Dantas o solo tem caráter coeso e, no lote União, o aumento de densidade observado em subsuperfície é compatível com o adensamento de solos com textura arenosa, não se caracterizando, portanto, uma camada coesa.

\section{Porosidade}

A distribuição do tamanho dos poros e a porosidade total apresentados na Tabela 2, ressaltam grandes diferenças entre as áreas avaliadas quanto a esse atributo físico do solo. Enquanto no lote União ocorre apenas leve redução na porosidade total e macroporosidade entre 0,30 e $0,60 \mathrm{~m}$, em H. Dantas observa-se forte redução na macroporosidade entre 0,20 e 0,40 m e entre 1,0 e 1,20 m. A redução da macroporosidade nesses dois pontos do perfil indica, juntamente com os elevados valores de densidade do solo (Figura 3), a existência de camadas adensadas, nessas profundidades.

Tabela 3. Água disponível nas duas áreas e profundidades estudadas do Distrito de Irrigação Platô de Neópolis, SE

\begin{tabular}{lcc}
\multicolumn{1}{c}{ Lotes } & $\begin{array}{c}\text { Profundidade } \\
(\mathrm{m})\end{array}$ & $\begin{array}{c}\text { Água disponível* } \\
\left(\mathrm{m}^{3} \mathrm{~m}^{-3}\right)\end{array}$ \\
\hline União & $0-0,15$ & 0,053 \\
& $0,15-0,30$ & 0,064 \\
& $0,30-0,60$ & 0,060 \\
& $0,60-0,90$ & 0,067 \\
& $0,90-1,20$ & 0,061 \\
\hline H. Dantas & $0-0,20$ & 0,038 \\
& $0,20-0,40$ & 0,050 \\
& $0,40-0,60$ & 0,039 \\
& $0,60-0,80$ & 0,054 \\
& $0,80-1,00$ & 0,045 \\
& $1,00-1,20$ & 0,039 \\
\hline
\end{tabular}

* Para transformar em percentagem, multiplicar por 100

A redução do volume total de poros e, principalmente, de macroporos, é uma das principais manifestações do caráter 
coeso dos solos dos Tabuleiros Costeiros. Neste sentido, estudo de correlação entre vários atributos físicos nesse ecossistema, desenvolvido por Souza et al. (2001), demonstrou a necessidade de medição do espaço poroso na avaliação de camadas ou horizontes adensados. Da mesma forma, Nascimento (2001) concluiu que a variação da densidade do solo no horizonte superficial é um índice de degradação do solo nos Tabuleiros Costeiros, uma vez que a elevação da densidade apresentou correlação negativa com volume de poros.

O baixo volume de macroporos do solo em H. Dantas, comparativamente ao solo do lote União, se reflete em menor teor de água disponível (Tabela 3), principalmente nas camadas mais adensadas, confirmando a tese de que as camadas coesas têm forte influência não apenas na redução da aeração mas, também, no movimento e retenção de água no solo e na sua disponibilidade para as plantas. Esses fatores são de grande importância nos sistemas agrícolas como um todo, sobretudo em sistemas irrigados por sua interferência na freqüência de irrigação e volume de água aplicado nos cultivos.

\section{Retenção de água no solo}

Com relação a tal atributo, Libardi (2002) ressalta a importância de estudos detalhados da caracterização hídrica dos solos dos Tabuleiros Costeiros, em particular no que diz respeito às propriedades de retenção (curva de retenção) e de transmissão (condutividade e difusividade hidráulica) de água no solo; alerta, ainda, que os estudos devem ser realizados por longo período para que se tenha uma idéia correta do regime hídrico no perfil.

As curvas de retenção de água no solo realizadas nesse estudo (Fig. 4A e B), são típicas de solos arenosos, principal-
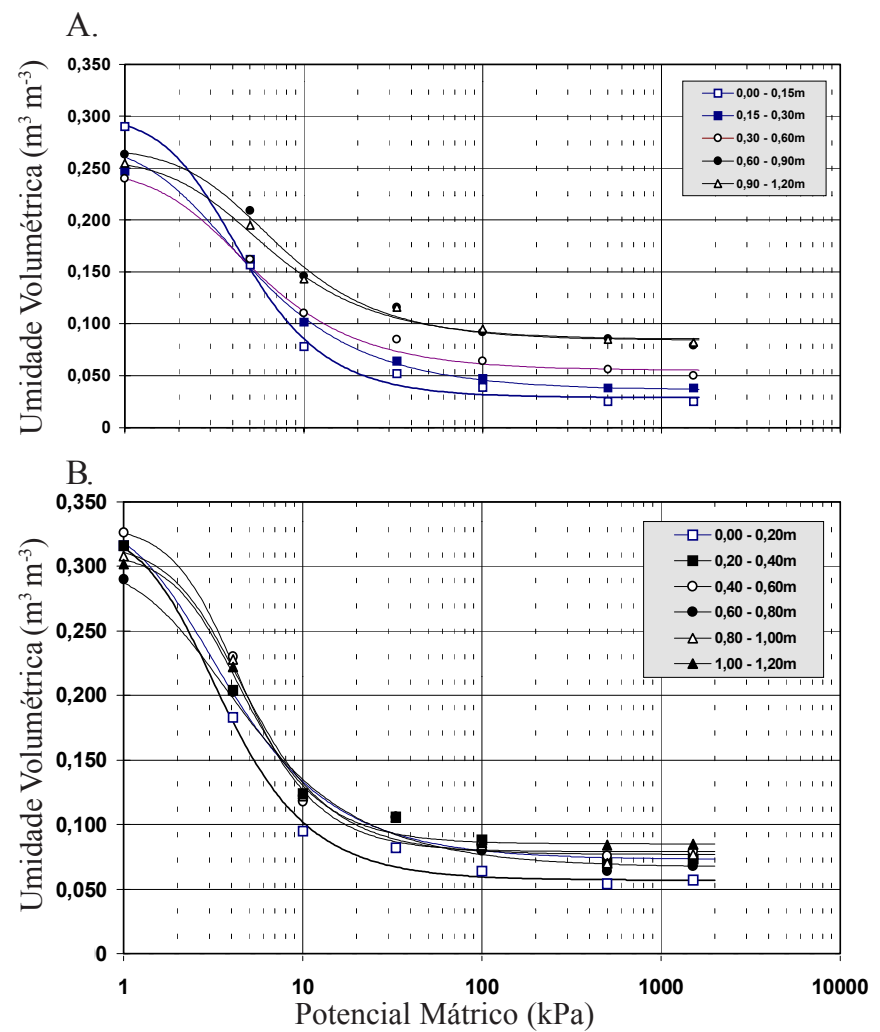

Figura 4. Curvas de retenção de água no solo, (A) Lote União e (B) Lote H. Dantas do Distrito de Irrigação Platô de Neópolis, SE mente no solo de H. Dantas onde a umidade cai mais bruscamente com o aumento da tensão aplicada. Apesar da diferença de formato, as curvas apresentam comportamento semelhante quanto à capacidade de retenção de água nas diferentes tensões aplicadas. A queda mais acentuada da umidade em $\mathrm{H}$. Dantas, em relação ao lote União, entre 0 e $10 \mathrm{kPa}$ se deve, sem dúvida, à maior concentração de frações de areia com maior diâmetro na camada superficial do solo.

Apesar dessa aparente homogeneidade, é possível se verificar, nas Figuras $4 \mathrm{~A}$ e B, diferenças sutis, porém significativas, no contexto de retenção de umidade a partir da tensão de $10 \mathrm{kPa}$. Neste ponto, apenas nas profundidades maiores que $0,30 \mathrm{~m}$, a retenção de água nas duas áreas é equivalente, apresentando-se distinta nas camadas mais superficiais do solo, cujo comportamento, diferenciado das curvas de retenção na zona mais superficial do solo exercerá, provavelmente, forte influência no manejo da irrigação dos dois lotes, tanto no volume de água aplicado quanto na freqüência de irrigação por se concentrar, nessa faixa de solo, a maior parte do sistema radicular das fruteiras.

\section{CONCLUSÕES}

1. As diferenças observadas nas propriedades físicas do solo nas duas áreas estudadas e as alterações que possivelmente influenciarão nos fatores físicos de crescimento, são um indicativo de que, apesar da homogeneidade da paisagem, são necessários cuidados especiais na tomada de decisão quanto às práticas de manejo do solo e da irrigação.

2. A existência de camadas adensadas próximas à superfície do solo, associadas ao regime climático da região, é uma indicação de que deverão ocorrer situações diferenciadas quanto ao desenvolvimento das fruteiras implantadas no Distrito de Irrigação Platô de Neópolis, seja em virtude das alterações no regime hídrico do solo ou da elevada resistência mecânica que oferecem à penetração das raízes.

\section{LITERATURA CITADA}

Araujo Filho, J.C. de. Investigações preliminares sobre a pedogênese de horizontes coesos em solos dos tabuleiros costeiros do Nordeste do Brasil. In: Cintra, F.L.D; Anjos, J.L. dos; Ivo, W.M.P. de M. (org.) Workshop Coesão em Solos dos Tabuleiros Costeiros. Aracaju, SE: Embrapa Tabuleiros Costeiros, 2001, p.123-139.

Cintra, F.L.D. Disponibilidade de água no solo para portaenxertos de citros em ecossistema de Tabuleiro Costeiro. Piracicaba: ESALQ/USP, 1997. 90p. Tese Doutorado

Cuenca, M.A.G. Importância econômica dos Tabuleiros Costeiros Nordestinos na agropecuária da região. Aracaju, SE: Embrapa Tabuleiros Costeiros, 2001. 28p. Série Documentos, 31

Dourado Neto, D.; van Lier, Q.J.; Botrel, T.A.; Libardi, P.L. Programa para confecção da curva de retenção de água no solo utilizando o modelo de van Genuchten. Engenharia Rural, Piracicaba, v.1, p.92-102, 1990. 
EMBRAPA. Serviço Nacional de Levantamento e Conservação do Solo. Manual de métodos de análise de solo. 2 ed. Rio de Janeiro, 1997.212p.

Forsythe, W.M. Las propriedades fisicas, los fatores físicos de crecimiento y la productividad del suelo. Fitotecnia Latinoamericana. San Jose, v.4, n.2, 1967.

Libardi, P.L. Dinâmica da água nos solos de tabuleiro. In: Araujo, Q.R. de. (Org.). 500 anos de uso do solo no Brasil. Ilhéus: UESC, 2002.p.581-596.

Matsura, E.E.; Javarez Júnior, A; Gomes, E.P.; Souza, C.F.; Aplicações da técnica de TDR na agricultura. Campinas: UNICAMP/FEAGRI, 2001.178p.

Nascimento, G.B. do. Caracterização dos solos e avaliação de propriedades edáficas em ambientes de Tabuleiros Costeiros da região Norte Fluminense (RJ). Rio de Janeiro: UFRRJ, 2001, 162p. Dissertação Mestrado
Ribeiro, L.P. Primeiras avaliações sobre a gênese dos solos coesos da região de Cruz das Almas, BA. In: Table rounde sur l'organization et dinamique interne de la coverture pedologique. Caen: CNRS, 1991,35p.

Ribeiro, M.R. Características morfológicas dos horizontes coesos dos solos dos Tabuleiros Costeiros. In: Cintra, F.L.D; Anjos, J.L. dos; Ivo, W.M.P. de M. Workshop Coesão em Solos dos Tabuleiros Costeiros. Aracaju: Embrapa Tabuleiros Costeiros, 2001.p.161-168.

Souza, L. da S.; Souza, L.D.; Caldas, R.C. Identificação da coesão com base em atributos físicos convencionais em solos dos Tabuleiros Costeiros. In: Cintra, F.L.D; Anjos, J.L. dos; Ivo, W.M.P. de M. (eds) Workshop Coesão em Solos dos Tabuleiros Costeiros, Aracaju: Embrapa Tabuleiros Costeiros, 2001. p.169-190.

van Genuchten, M.T. A closed-form equation for predicting the hydraulic conductivity of unsaturated soils. Soil Science Society of America Journal, Madison, v.44, p.892-897, 1980. 